University of Nebraska - Lincoln

DigitalCommons@University of Nebraska - Lincoln

1999

\title{
Sociality and Social Learning in Two Species of Corvids: The Pinyon Jay (Gymnorhinus cyanocephalus) and the Clark's Nutcracker (Nucifraga columbiana)
}

Jennifer J. Templeton

Knox College, jtemplet@knox.edu

Alan Kamil

University of Nebraska - Lincoln, akamil1@unl.edu

Russell P. Balda

Northern Arizona University, Russell.Balda@nau.edu

Follow this and additional works at: https://digitalcommons.unl.edu/bioscibehavior

Part of the Behavior and Ethology Commons

Templeton, Jennifer J.; Kamil, Alan; and Balda, Russell P., "Sociality and Social Learning in Two Species of Corvids: The Pinyon Jay (Gymnorhinus cyanocephalus) and the Clark's Nutcracker (Nucifraga columbiana)" (1999). Papers in Behavior and Biological Sciences. 71.

https://digitalcommons.unl.edu/bioscibehavior/71

This Article is brought to you for free and open access by the Papers in the Biological Sciences at DigitalCommons@University of Nebraska - Lincoln. It has been accepted for inclusion in Papers in Behavior and Biological Sciences by an authorized administrator of DigitalCommons@University of Nebraska - Lincoln. 
Published in Journal of Comparative Psychology 113:4 (1999), pp. 450-455; doi: 10.1037/0735-7036.113.4.450 Copyright (C) 1999 American Psychological Association. Used by permission. "This article may not exactly replicate the final version published in the APA journal. It is not the copy of record." http://www.apa.org/journals/jcp/

This research was supported in part by National Science Foundation Grants OSR9255225, DEB9504103, and DEB9421807 and by a Fonds Chercheurs et Aide à la Recherche (Québec) postdoctoral fellowship. The authors thank Kerri Bestul for testing the animals and Chris Smith for caring for them.

\title{
Sociality and Social Learning in Two Species of Corvids: The Pinyon Jay (Gymnorhinus cyanocephalus) and the Clark's Nutcracker (Nucifraga columbiana)
}

\author{
Jennifer J. Templeton, School of Biological Sciences, University of Nebraska-Lincoln \\ Alan C. Kamil, School of Biological Sciences, University of Nebraska-Lincoln \\ Russell P. Balda, Department of Biological Sciences, Northern Arizona University \\ Corresponding author - J. J. Templeton, Department of Biology, Franklin and Marshall College, \\ Lancaster, Pennsylvania 17604-3003
}

\begin{abstract}
The hypothesis that social learning is an adaptive specialization for social living predicts that social species should learn better socially than they do individually, but that nonsocial species should not exhibit a similar enhancement of performance under social learning conditions. The authors compared individual and social learning abilities in 2 corvid species: the highly social pinyon jay (Gymnorhinus cyanocephalus) and the less social Clark's nutcracker (Nucifraga columbiana). The birds were tested on 2 different tasks under individual and social learning conditions. Half learned a motor task individually and a discrimination task socially; the other half learned the motor task socially and the discrimination task individually. Pinyon jays learned faster socially than they did individually, but nutcrackers performed equally well under both learning conditions. Results support the hypothesis that social learning is an adaptive specialization for social living in pinyon jays.
\end{abstract}

Forty years ago, Klopfer (1959) hypothesized that social learning was an adaptive specialization to group living; subsequent tests of this hypothesis in birds (Klopfer, 1961) and primates (Cambefort, 1981; Jouventin, Pasteur, \& Cambefort, 1976) provided some initial support for this view. Recently, however, Lefebvre (1996) and Lefebvre and Giraldeau (1996) have cautioned that experimental comparisons of social learning can often be inconclusive, especially if species are compared in terms of their social learning abilities alone. In such cases, several other factors could confound the results. For example, apparent differences in social learning abilities could be due to differences in the species' foraging ecologies or opportunism, or they could simply be due to the way the animals respond to experimental tasks (Kamil, 1988; Lefebvre \& Giraldeau, 1996; Shettleworth, 1993) and not due to any differences in sociality per se.

Rather than making between-species comparisons of social learning abilities, therefore, Lefebvre and Giraldeau (1996) encourage within-species comparisons of individual and social learning abilities. This switch in focus allows one to test whether social learning does indeed enhance the acquisition of novel skills within social species but not within nonsocial species. This point is clearly illustrated by Lefebvre, Palameta, and Hatch (1996), who found group living to be associated with species differences in individual as well as social learning abilities in two species of columbids. In other words, the group-living species learned a novel skill just as well under individual conditions as it did under so- cial conditions. This result suggested either that the groupliving species may have been better learners in general and not better social learners in particular or, alternatively, that the group-living species may simply have shown better performance in captivity than the nonsocial species.

As Lefebvre and Giraldeau (1996) argued, therefore, it is neither necessary nor appropriate to determine whether a social species is superior to a nonsocial species in its social learning abilities. Instead, the social species should show an enhanced acquisition of novel skills under social learning conditions compared with its acquisition of novel skills under individual learning conditions, whereas the nonsocial species should not. Thus, a significant species-by-learning condition interaction is necessary to support the hypothesis that social learning is an adaptive specialization to the demands of group living (Lefebvre \& Giraldeau, 1996).

In 1997, Balda, Kamil, and Bednekoff(1999z) proposed that certain specialized cognitive abilities, including the use of social information, should be favored in social corvids. In the present article, we present a preliminary test of the hypothesis that social learning is an adaptive specialization to group living in corvids by carrying out an experimental comparison of individual and social learning abilities within pinyon jays (Gymnorhinus cyanocephalus) and within Clark's nutcrackers (Nucifraga columbiana), two members of the tribe Corvini (Sibley \& Ahlquist, 1990) that differ markedly in their degree of sociality (Balda et al., 1997). Pinyon jays are highly social corvids. Indeed, they are considered to "represent a pinnacle in the evolution of avian sociality" 
(Marzluff \& Balda, 1992, p. 285). They live in large colonies that can number in the hundreds, each colony consisting of smaller family groups that exhibit cooperative breeding and highly complex social interactions. Cohesiveness of the group is paramount to the pinyon jay, and many behaviors occur synchronously. Virtually all activities occur in a social context, even from a young age when juveniles form large crèches of 20 to 60 birds (Marzluff \& Balda, 1992).

Although not solitary, nutcrackers are much less social than pinyon jays. They form pairs in the breeding season in late winter and early spring during which they defend nesting territories against intruding conspecifics, and they can also be seen in small family groups of two to four individuals in the spring and early summer (Mewaldt, 1956). On rare occasions, however, irruptions occur in which large flocks of nutcrackers have moved to lower elevations in response to the failure of cone crops (Davis \& Williams, 1957; Vander Wall \& Balda, 1977).

By choosing to use pinyon jays and Clark's nutcrackers as the subjects of our study, we hoped to reduce or eliminate some of the factors that could potentially confound the results we would obtain (Lefebvre \& Giraldeau, 1996). Perhaps the most important of these confounds is the possibility that the species under consideration differ not only in the ecological covariate predicted to be associated with the learning specialization (in this case, degree of sociality) but in other respects as well, such as foraging ecology and opportunism (Laland \& Plotkin, 1990; Lefebvre et al., 1996). For example, although they share similar habitats, a comparison between pinyon jays and western scrub jays (Aphelocoma californica) would have to take into consideration the fact that these two species differ markedly in their foraging ecologies, particularly with respect to food-storing behavior and spatial memory abilities (Balda et al., 1997). Pinyon jays and nutcrackers, however, share very similar foraging ecologies and habitats, with both species being highly dependent on pine seeds that they harvest and cache in the fall for future recovery throughout the following winter and spring (Vander Wall \& Balda, 1981).

Although it is more difficult to provide an accurate measure of opportunism, pinyon jays and nutcrackers exhibit a comparable degree of opportunistic behavior as well, particularly with respect to foraging. Both species specialize on pine seeds in winter but have quite omnivorous summer diets, including conifer seeds, fruits, insects, bird eggs, and nestlings (Ehrlich, Dobkin, \& Wheye, 1988). The two species also take advantage of human-provided food sources, with pinyon jays being regular visitors to backyard feeders (Marzluff \& Balda, 1992) and nutcrackers exploiting campgrounds and picnic tables, thus earning the nickname "camp robber."

Both species also share the same repertoire of motor abilities, another factor that could potentially influence the ability to acquire certain foraging skills (Lefebvre, Templeton, Brown, \& Koelle, 1997). Unlike other corvids, their sharp, pointed beaks are well-adapted to extracting pine seeds from unopened cones; they are also adept at both burying and uncovering caches of hidden pine seeds (Vander Wall \& Balda, 1981). Similarly, both species exhibit comparable spatial memory capacities, a cognitive ability that reflects their strong dependence on cached food (Balda \& Kamil, 1989).

Experimental comparisons of cognitive abilities such as learning are often problematic because interspecific differences in learning can sometimes be attributed to species differences in response to the experimental task itself (Kamil, 1988; Lefebvre \& Giraldeau, 1996; Shettleworth, 1993). In an attempt to circumvent this potentially confounding factor, we used two different tasks: a motor task and a discrimination task. In addition, half the birds learned the motor task individually and the discrimination task socially; the other half learned the motor task socially and the discrimination task individually. We predicted that pinyon jays would acquire the novel skills more rapidly under social learning conditions than they would under individual learning conditions and that nutcrackers would show either the opposite pattern or no difference.

\section{Method}

\section{Subjects}

Clark's nutcrackers ( $n=6$; Nucifraga columbiana) and pinyon jays ( $n=6$; Gymnorhinus cyanocephalus) were used as naive subjects. The birds were all captured as adults in the wild but varied somewhat in their previous experience in the laboratory. The 6 nutcrackers had been captured 2 to $9(M=6)$ years before the start of the experiment and had served in both operant and cacherecovery experiments. Four of the pinyon jays had been captured 5 to $7(M=6)$ years before the start of the experiment and had served in the same or similar operant and cache-recovery experiments as the nutcrackers. The other 2 pinyon jay subjects had been in captivity for 1 year and had some training in an operant experiment. In addition to the 12 subjects, a nutcracker and a pinyon jay were trained as demonstrators for the first 2 subjects of each species. The nutcracker had been in captivity for 11 years and had served in numerous experiments. The pinyon jay had been in captivity for 1 year and was experimentally naive. Two of the nutcracker subjects and 2 of the pinyon jay subjects also served as demonstrators for 2 subjects each after their tests had been completed. Thus, there were three different demonstrators for each species.

All birds were housed individually and kept on a 10:14-hr light-dark cycle. They were maintained at $85 \%$ to $90 \%$ of their free-feeding weight throughout the experiment by controlled daily feeding. The diet included pinyon pine seeds, sunflower seeds, mealworms, and parrot pellets (Lafebers' Premium Daily Diet for Parrots; Lafebers, Odell, IL).

\section{Apparatus}

There were two experimental tasks: a motor task and a discrimination task. The apparatus for the motor task consisted of a single well $(1.0 \mathrm{~cm}$ deep, $3.5 \mathrm{~cm}$ diameter $)$ drilled in a light-gray block of wood $(28.0 \times 14.0 \times 3.5 \mathrm{~cm}$ high) and covered by a white lid (1.0 cm high, $6.5 \mathrm{~cm}$ diameter). When the lid was pecked off, a single pine seed could be obtained from the well. The apparatus for the discrimination task consisted of two stimulus lids that covered two wells, $10.0 \mathrm{~cm}$ apart in a block of wood. One stimulus lid had a green square on a purple background; the other had a purple square on a green background. For each apparatus, weights $(30 \mathrm{~g})$ were taped to the inside of the lids, making them heavy and thus difficult to knock off accidentally. 
During testing, the subject was held in a wire cage $(60.0 \times 60.0$ $\times 60.0 \mathrm{~cm}$ high) facing a demonstrator of the same species held in a similar cage. For the motor task, both cages had a single opening in front $(6.5 \times 6.5 \mathrm{~cm})$ through which the birds could access the apparatus, which was placed in front of the opening. For the discrimination task, there were two adjacent openings, $2 \mathrm{~cm}$ apart; each lid was adjacent to each opening. The subject and demonstrator cages were separated by two $12-\mathrm{cm}$ wide trays that were used to slide the apparatus into place. The cages were illuminated by two spotlights during trials. The experimenter, who was naive to the predictions of the study, observed trials from behind a blind.

\section{Training}

Each demonstrator was first trained to peck off a single white lid which had a small black sticker $(2 \times 1 \mathrm{~cm})$ on the edge facing it. Once it was pecking off the lid and eating the concealed nut within $10 \mathrm{~s}$, the demonstrator was then trained to peck off one of two white lids; the lid with the black sticker concealed the pine seed. Finally, the demonstrator was trained to peck off one of the two colored stimulus lids within $10 \mathrm{~s}$. Again, the demonstrator had to learn that the lid with the black sticker was rewarded with a hidden pine seed; the pattern and position of the rewarded lid was varied randomly over presentations. Lids used with subject birds never had a black sticker.

\section{Experimental Procedure}

The experiment had three consecutive phases: eating, motor task, and discrimination task. In the eating phase, subjects were simply required to take and eat a pine seed that was clearly visible in an open well; the lid was adjacent to but not covering the hole. The demonstrator was present during these trials but was concealed behind a visual barrier during presentations of the foraging apparatus. There were 5 trials per day with an intertrial interval (ITI) of $2 \mathrm{~min}$. When a subject met the criterion of eating from the well for 10 trials in a row, the motor task began on the following day. The purpose of the eating phase was two-fold. It provided a measure of the subjects' motivation and neophobia to the experimental setup, and it also provided the subjects with nonsocial feeding cues from the foraging apparatus that could potentially be used to promote individual learning of the subsequent motor task (Lefebvre et al., 1996).

For the motor task, a social learning trial consisted of a single demonstration followed by a single test. During the demonstration, the experimenter would slide the apparatus in front of the demonstrator, who pecked off the lid and ate the nut. The apparatus was then slowly removed and a visual barrier was placed between the 2 birds. After a delay of $20 \mathrm{~s}$, the replenished apparatus was pushed in front of the subject, who had 5 min to peck off the lid and eat. Trials were similar for the individual learning condition, but the demonstrator was not presented with the task during the demonstration part of a trial. There were 5 trials a day; the ITI was $2 \mathrm{~min}$. Trials continued in both conditions until a subject either pecked off the lid for 5 trials in a row or completed a maximum of 40 trials. Subjects that did not learn the motor task within the 40 trials were trained to do so before the start of the discrimination phase.

For the discrimination task, the rewarded stimulus lid for each subject was determined by a single presentation of the two unrewarded lids before the start of trials; to avoid any initial pattern bias, the lid pattern not selected by the subject was designated as the correct pattern for that bird. A daily session in the social discrimination condition consisted of eight consecutive lid choices by the demonstrator followed by four consecutive lid choices by the subject. The rewarded lid was presented to the demonstrator four times on each side in random order, with $30 \mathrm{~s}$ between each presentation. The rewarded lid had the black sticker on the edge facing the demonstrator (invisible to the subject); the other lid was taped down on one side to prevent the demonstrator from knocking it off by mistake. All demonstrators pecked the correct lid off the well within $10 \mathrm{~s}$. Following the eighth demonstration, a visual barrier was placed between the 2 birds. After a delay of $1 \mathrm{~min}$, the replenished apparatus was pushed in front of the subject for the first of four choice trials; the demonstrator's black sticker had been removed from the rewarded lid, and the incorrect lid was not taped down. There was an ITI of $30 \mathrm{~s}$.

Sessions in the individual discrimination condition consisted of 4 choice trials per day; the demonstrator was present but was hidden behind the barrier during these trials. The learning criterion and trial limit for the discrimination task were the same as for the motor task; trials in both individual and social conditions continued until the subject either pecked off the correct lid for 5 trials in a row or completed a maximum of 40 trials.

The development of side biases is a common occurrence during the learning of a discrimination task, and a standard procedure was used to eliminate it. When a subject selected the same side for six trials in a row, a session of remedial presentations with the correct lid in the nonpreferred position was given to the bird until the correct lid was chosen. These remedial presentations were not preceded by demonstrations and did not count as trials. The number of times a remedial session was required to eliminate bias was recorded for each individual.

Two nutcracker and 2 pinyon jay subjects went through the three experimental phases concurrently. All of the subjects first learned the eating task individually. Then half of the subjects learned the motor task individually and the discrimination task socially; the other half learned the motor task socially and the discrimination task individually. Assignment of subjects to these two treatment orders was arbitrary. Following the completion of testing, the heavier individual from each pair of subjects was trained as a demonstrator for the next pair of subjects. None of the demonstrators was caught at the same place as the 2 birds for which it performed.

Data were collected from demonstrators and subjects in each phase of the study. These data included the latency to peck off the lid or eat or both, the number of pecks made to the lid, which lid pattern was selected, and the side it was on. Acquisition of the experimental tasks was measured as the number of trials required to reach the criterion of a correct response for five trials in a row. To determine whether subjects were paying attention to the demonstrator, we obtained mean attention scores from written descriptions or from videotapes of each subject during all demonstrations of the motor or discrimination task, respectively. There were six attention scores: 0 = facing away on perch, $1=$ looking over shoulder on perch, 2 = facing forward on perch, 3 = facing forward on floor, $4=$ head at opening, and $5=$ head through opening.

\section{Results}

\section{Eating Task}

Within each eating task trial, pinyon jay subjects took significantly longer to take the nut $(M=12.4, S E= \pm 3.5 \mathrm{~s})$ than the nutcracker subjects $(M=2.4, S E= \pm 0.4 \mathrm{~s}), t(10)=$ $-2.85, p=.017$. However, there was no significant difference in the number of trials required for the two species to meet the eating task criterion; pinyon jays took a mean of $14.2(S E= \pm 1.6)$ trials, whereas nutcrackers took a mean of $14.3(S E= \pm 2.6)$ trials, $t(10)=0.06, p=.957$. Thus, although 
the pinyon jays were possibly more neophobic or less motivated in the experimental apparatus than the nutcrackers, it did not deter them from reaching the criterion in a similar amount of time.

\section{Motor and Discrimination Tasks}

Demonstrator performance - Although the pinyon jay demonstrators took somewhat longer $(M=7.1, S E= \pm 0.5$ s) than the nutcracker demonstrators $(M=3.8, S E= \pm 3.1 \mathrm{~s})$ to peck off the lid during the motor task phase, the difference was not significant, $t(4)=-1.92, p=.128$. There was also no significant difference in the mean number of pecks made to the lid by the pinyon jay $(M=2.9, S E= \pm 0.9$ pecks $)$ and nutcracker $(M=3.3, S E= \pm 1.2$ pecks $)$ demonstrators, $t(4)=0.45, p=.677$. Similarly, the latency of demonstrators to peck off the rewarded lid during the discrimination task did not differ significantly between pinyon jays $(M=3.6$, $S E= \pm 0.2 \mathrm{~s})$ and nutcrackers $(M=2.3, S E= \pm 1.5 \mathrm{~s}), t(4)=$ $-1.45, p=.221$. There was also no significant difference in the number of pecks made to the lid by pinyon jays $(M=$ 3.6, $S E= \pm 1.1$ pecks $)$ and nutcrackers $(M=3.1, S E= \pm 0.9$ pecks) during their demonstrations, $t(4)=-0.58, p=.595$. Thus, although the power of the tests was low, the demonstrators of the two species did not differ significantly in any of the measured behaviors.

Subject performance - Only 2 pinyon jays met the learning criterion in the individual condition, whereas all 6 pinyon jays met this criterion in the social condition. In contrast, 5 of the 6 nutcrackers reached criterion in the individual condition, but 2 failed to do so in the social condition. Because of a lack of an effect of learning condition in the discrimination task (see below), data from both tasks were pooled for analysis. Figure 1 shows the mean number of trials each species required to reach the criterion under social and individual learning conditions. These data were analyzed with a two-way repeated measures analysis of variance (ANOVA) in which we examined the effect of species and learning condition only. There was no significant effect of either species or learning condition, but there was a significant interaction between the two, $F(1,10)=20.33, p=.001$. Subsequent analyses showed that pinyon jays learned the tasks significantly more quickly under social learning conditions than they did under individual learning conditions, paired $t$ test: $t(5)=5.19, p=.003$. In contrast, nutcrackers exhibited slightly better individual than social learning abilities; however, this trend was not significant, $t(5)=-2.12, p$ $=.087$. The lack of a significant difference in their individual and social learning scores suggests that the nutcrackers may not have been learning socially at all but were learning individually even in the social condition. This possibility does have some anecdotal support. For example, 1 of the 3 nutcrackers that learned the motor task in the social condition did not use the same lid-pecking technique of its demonstrator but instead pulled the lid toward itself before obtaining the nut. None of the pinyon jays behaved differently from their demonstrators.

The significant species-by-learning condition interaction obtained with the pooled task data held true for the motor

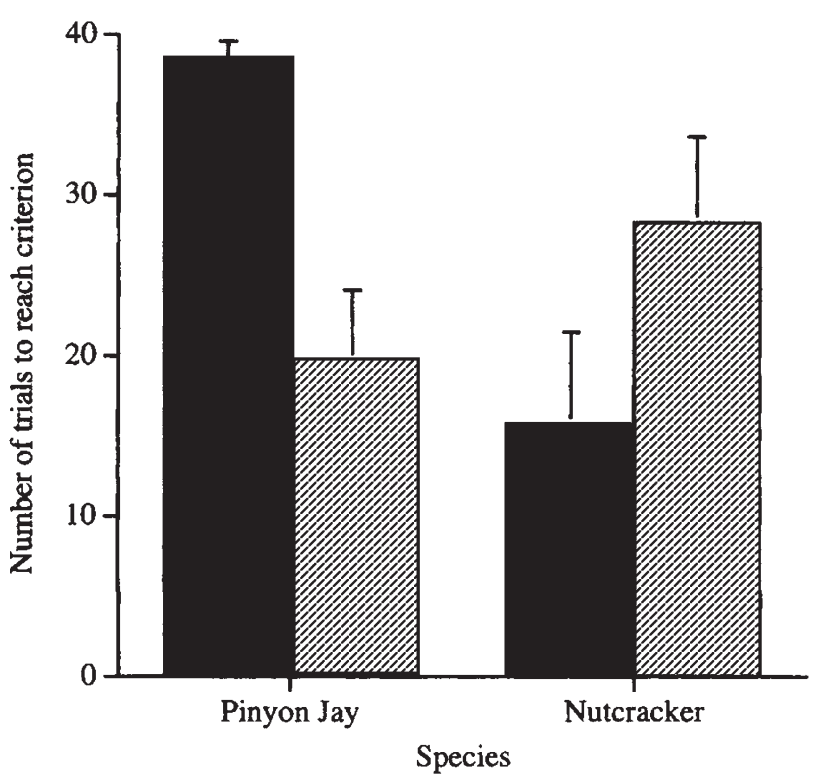

Figure 1. Number of trials $( \pm S E$ ) required by Clark's nutcrackers and pinyon jays to reach the learning criterion under both individual and social learning conditions. Data from motor and discrimination tasks are combined. Solid bars represent the individual learning task; hatched bars represent the social learning task

task; a two-way ANOVA on the motor task data alone showed a significant interaction between species and learning condition, $F(1,8)=13.19, p=.007$. However, a similar analysis on discrimination task data alone found no significant interaction, $F(1,8)=2.18, p=.178$. Although the social learning hypothesis actually makes no predictions about interspecific learning differences, we did carry out these comparisons. Pinyon jays took fewer trials than nutcrackers to learn socially, but this difference was not significant, $t(10)=1.24, p=.243$. However, pinyon jays took significantly more trials than nutcrackers to learn the tasks individually, $t(10)=-3.89, p=.003$.

Not surprisingly, all subjects developed side biases during both conditions of the discrimination task. Pinyon jays required a few more sessions of remedial presentations ( $M$ $=4.0, S E= \pm 1.9$ sessions $)$ than did nutcrackers $(M=2.7, S E$ $= \pm 2.4$ sessions) to eliminate the bias, but this difference was not significant, $t(10)=-1.06, p=.313$. The apparent attention paid to the demonstrator during social learning conditions did not differ between the two species either. Pinyon jays had a mean attention score of $3.5(S E= \pm 0.5)$, whereas the attention score for the nutcrackers was 3.2 (SE $= \pm 0.3), t(10)=-0.77, p=.459$. Interestingly, the 2 nutcrackers that did not learn at all in the social condition had the highest and third highest attention scores; thus, it is unlikely that their poor performance was simply due to a lack of attention.

\section{Discussion}

The pinyon jays in this study acquired the motor skill more rapidly under social learning conditions than they 
did under individual learning conditions, whereas the nutcrackers showed no significant differences in acquisition rates between individual and social conditions. The consequent species-by-learning condition interaction therefore is consistent with the hypothesis that social learning may be an adaptive specialization to social living, at least in pinyon jays. Although the pinyon jays took fewer trials than the nutcrackers to reach the criterion under social learning conditions, this difference was not significant. Thus, if the predicted learning differences had been based on interspecific differences in social learning abilities rather than on relative measures of individual and social learning within each species, the hypothesis would not have been supported. This finding clearly illustrates how crucial it is to compare individual and social learning abilities within rather than between species (Lefebvre \& Giraldeau, 1996).

\section{Effect of Task Type on Performance}

The enhanced learning exhibited by the pinyon jays in the social learning condition was only true for the motor task and not for the discrimination task. This result suggests that the jays were paying attention to the demonstrator and its behavior but not to the specific details of the stimuli with which it was interacting. One might expect such an effect to be particularly pronounced in highly social species such as pinyon jays, in which the tendency to synchronize behaviors with others starts at an early age (Marzluff \& Balda, 1992). In the social condition of the motor task, for example, observing the demonstrator peck off the lid increased the probability that the pinyon jay subject would attempt a similar movement during its subsequent trial. In the individual condition of the motor task, however, the demonstrator did nothing during the demonstration period, and subsequently the observer did nothing as well; indeed, none of the 3 pinyon jays in the individual learning condition of the motor task acquired the response, despite their prior experience at feeding from the open well. Given the potential problem with the discrimination task, it would be worth considering alternative learning tasks that would require closer observation of the demonstrator, for example, observing different motor techniques for the same task (Heyes \& Dawson, 1990). In addition, it might be better not to have a nonperforming demonstrator in the individual learning condition because this may inhibit subject performance in social species.

\section{Scramble Competition and Social Learning}

The results of our study are consistent with the scramble competition hypothesis (Dolman, Templeton, \& Lefebvre, 1996; Lefebvre et al., 1996, 1997), which predicts that species exhibiting scramble competition over foraging resources will have enhanced social learning abilities, whereas species exhibiting interference competition will not show a comparable enhancement. Pinyon jays scramble compete for food, with as many as 100 individuals feeding together at one time. Although a few aggressive interactions can occur at feeding sites, these are relatively subdued with highly ritualized, submissive postures exhibited by subordinates in response to mild threats from dominant birds (Marzluff \& Balda, 1992). Most importantly, subordinates are allowed either to remain at or to return to feeding sites even after an exchange of these displays. In contrast, nutcrackers exhibit interference competition at feeding areas both in the field (personal observations of Jennifer J. Templeton and Russell P. Balda) and in the laboratory (personal observations of Russell P. Balda); on some occasions, intense fights can ensue, resulting in an individual being restricted from a specific foraging area.

\section{Future Tests of Social Cognition}

Although the results of our study suggest that social learning may be an adaptive specialization to social living in pinyon jays, an alternative hypothesis is that enhanced learning under social conditions is simply the result of ontogeny. In particular, living in social groups could train pinyon jays to become highly responsive to social information. This alternative explanation is suggested by the work of Dolman et al. (1996), which showed that two different populations of Zenaida doves (Zenaida aurita) acquired social information from conspecifics or heterospecifics when the population was gregarious or territorial, respectively. To test this alternative hypothesis, it would be necessary to raise pinyon jays in captivity under social or asocial conditions and to compare the social and individual learning abilities of both groups.

The findings of the present study are consistent with those of Bednekoff and Balda (1996, 1997), who showed that the highly social Mexican jay (Aphelocoma ultramarina) and the pinyon jay are both able to locate caches in which they have observed conspecifics hide food, whereas Clark's nutcrackers cannot. Thus, comparative experiments to date support the hypothesis that the use of social information should be favored in social corvids. However, Balda et al. (1997) have argued that the crucial test of this hypothesis will be to use abstract tasks that test for social skills (such as transitive inference) in a nonsocial context to allow for controlled comparisons between social and nonsocial species. To determine the generality of our findings, researchers should design future experiments in which they use a variety of novel tasks with different corvids.

\section{References}

Balda, R. P., \& Kamil, A. C. (1989). A comparative study of cache recovery by three corvid species. Animal Behaviour, 38, 486-495.

Balda, R. P., Kamil, A. C., \& Bednekoff, P. A. (1997). Predicting cognitive capacities from natural histories: Examples from four corvid species. Current Ornithology, 13, 33-66.

Bednekoff, P. A., \& Balda, R. P. (1996). Observational spatial memory in Clark's nutcrackers and Mexican jays. Animal Behaviour, 52, 833-839.

Bednekoff, P. A., \& Balda, R. P. (1997). Social caching and observational spatial memory in pinyon jays. Behaviour, 133, 807-826. 
Cambefort, J. P. (1981). Comparative study of culturally transmitted patterns of feeding habits in the chacma baboon (Papio ursinus) and the vervet monkey (Certhopithecus aethiops). Folia Primatologica, 36, 243-263.

Davis, J., \& Williams, L. (1957). Irruptions of the Clark's nutcracker in California. Condor, 59, 297-307.

Dolman, C., Templeton, J. J., \& Lefebvre, L. (1996). Mode of foraging competition is related to tutor preference in Zenaida aurita. Journal of Comparative Psychology, 110, 45-54.

Ehrlich, P., Dobkin, D. S., \& Wheye, D. (1988). The birder's handbook: A field guide to the natural history of North American birds. New York: Simon \& Schuster/Fireside Books.

Heyes, C. M., \& Dawson, G. R. (1990). A demonstration of observational learning using a bidirectional control. Quarterly Journal of Experimental Psychology, 42B, 59-71.

Jouventin, P., Pasteur, G., \& Cambefort, J. P. (1976). Observational learning of baboons and avoidance of mimics: Exploratory tests. Evolution, 31, 214-218.

Kamil, A. C. (1988). A synthetic approach to the study of animal intelligence. In D. W. Leger (Ed.), Comparative perspectives in modern psychology: Nebraska Symposium on Motivation (Vol. 35, (pp. 257-308). Lincoln: University of Nebraska Press.

Klopfer, P. H. (1959). Social interactions in discrimination learning with special reference to feeding behavior in birds. Behaviour, 14, 282-299.

Klopfer, P. H. (1961). Observational learning in birds: The establishment of behavioral modes. Behaviour, 17, 71-80.

Laland, K. N., \& Plotkin, H. C. (1990). Social learning and social transmission of foraging information in Norway rats (Rattus norvegicus). Animal Learning and Behaviour, 18, 246-251.
Lefebvre, L. (1996). Ecological correlates of social learning: Problems and solutions for the comparative method. Behavioural Processes, 35, 163-171.

Lefebvre, L., \& Giraldeau, L.-A. (1996). Is social learning an adaptive specialization?. In C. M. Heyes \& B. G. Galef, Jr. (Eds.), Social learning and the roots of culture. New York: Academic Press.

Lefebvre, L., Palameta, B., \& Hatch, K. K. (1996). Is group-living associated with social learning? A comparative test of a gregarious and a territorial columbid. Behaviour, 69, 1-21.

Lefebvre, L., Templeton, J. J., Brown, K., \& Koelle, M. (1997). Carib grackles imitate conspecific and Zenaida dove tutors. Behaviour, 134, 1003-1017.

Marzluff, J. M., \& Balda, R. P. (1992). The pinyon jay: Behavioral ecology of a colonial and cooperative corvid. London: Academic Press.

Mewaldt, L. R. (1956). Nesting behavior of the Clark's nutcracker. Condor, 58, 3-23.

Shettleworth, S. J. (1993). Where is the comparison in comparative cognition? Alternative research programs. Psychological Science, 4, 179-184.

Sibley, C. G., \& Ahlquist, J. E. (1990). Phylogeny and classification of birds. A study in molecular evolution. New Haven, CT: Yale University Press.

Vander Wall, S. B., \& Balda, R. P. (1977). Coadaptation of Clark's nutcracker and pinyon pine for efficient seed harvest and dispersal. Ecological Monographs, 47, 89-111.

Vander Wall, S. B., \& Balda, R. P. (1981). Ecology and evolution of food storage behavior in conifer-seed caching corvids. Zeitschrift für Tierpsychologie, 56, 217-242. 